\title{
The Relationship of Coaching Leadership and Innovation Behavior: Dual Mediation Model for Individuals and Teams across Levels
}

\author{
Xiaoxuan Zhang \\ Jinan University, Guangzhou, China \\ Email: 18848977934@163.com
}

How to cite this paper: Zhang, X. X. (2020). The Relationship of Coaching Leadership and Innovation Behavior: Dual Mediation Model for Individuals and Teams across Levels. Open Journal of Leadership, 9, 70-83.

https://doi.org/10.4236/oj1.2020.91005

Received: February 22, 2020

Accepted: March 13, 2020

Published: March 16, 2020

Copyright $\odot 2020$ by author(s) and Scientific Research Publishing Inc. This work is licensed under the Creative Commons Attribution International License (CC BY 4.0).

http://creativecommons.org/licenses/by/4.0/ (c) (i) Open Access

\begin{abstract}
In the face of the accelerated upgrading of the market and the increasingly fierce competition, innovation has become an important driving force for the survival and development of enterprises. As a new way of management and an important way to develop the ability of employees, coach leadership has its unique advantages in promoting employee innovation, and it has been paid more and more attention by scholars and practitioners. Based on the current situation of Chinese enterprise management, this study discusses the relationship between coaching leadership and employee innovation behavior, and explores the interactive mechanism from the team level and individual level. This study takes the on-the-job team leaders and their subordinates in enterprises in South China as the research object to explore and verify the effect of coaching leadership on employees' advice behavior and the intermediary mechanism of team mindfulness and employee innovation process input. The results show that: 1) coaching leadership has a significant positive impact on employee innovation behavior; 2) team mindfulness plays an intermediary role in the relationship between coaching leadership and employee innovation behavior; 3 ) employee innovation process engagement plays an intermediary role in the relationship between coaching leadership and employee innovation behavior; 4) team mindfulness has a significant positive impact on employees' innovation process engagement, and coaching leaders influence innovation behavior through the chain intermediary between team mindfulness and employees' innovation process engagement.
\end{abstract}

\section{Keywords}

Coaching Leadership, Team Mindfulness, Innovation Process Engagement, Innovation Behavior 


\section{Introduction}

Faced with the challenge of fast product upgrading and fierce market competition, innovation has become an important driving force for the survival and development of enterprises (Sacramento, Fay, \& West, 2013). Therefore, how to promote the innovative behavior of employees and maintain the vitality of enterprises in the fierce competition has become an issue of great concern in the practice of enterprises. Among the many factors that affect employees' innovation behavior, the role of leaders in employees' innovation behavior can't be ignored, and leadership style is one of the most important factors (Jung, Chow, \& $\mathrm{Wu}, 2003)$. Therefore, we start from the new leadership style to study its impact on employees' innovative behavior.

Under the new economic conditions and management background, the key to innovation lies in the improvement and breakthrough of employees' psychological model. Coaching leaders teach students in accordance with their aptitude and play a unique role in enlightening employees and enabling organizations and employees to achieve a win-win situation, which is in line with the characteristics of contemporary economy and society and the needs of the new generation of employees, and brings a lot of positive effects to enterprises and employees (Smither, London, Flautt, Vargas, \& Kucine, 2003; Özduran \& Tanova, 2017). Therefore, people pay more and more attention to the functional mechanism and positive influence of coaching leadership in enterprises.

Although the theoretical and practical circles have reached a consensus on the positive role of coaching leadership, the research on its specific mechanism is not perfect. In addition, at present, most of the research on leadership and innovation behavior stays at a single level of individual or team, and there are few cross-level studies. However, employees' innovative behavior is driven by a variety of factors, and single-layer variables cannot play a decisive role. Therefore, this study will explore the relationship between coaching leadership and employee innovation behavior, and explore the intermediary mechanism from different levels, enrich the research on coaching leadership and organizational innovation, and further promote the development of coaching leadership theory.

\section{Theory and Hypotheses}

Based on the resource conservation theory, Bakker and Demerouti (2017) put forward a complete job requirement-resource model, which explains how work requirements and work resources in the work environment affect organizational results through different paths. The primary core assumption of the job requirements-resource model is that all job characteristics can be divided into two categories-job requirements and job resources. Job requirements refer to the material, psychological, social or organizational requirements at work (Demerouti et al., 2001). Work resources refer to the material, psychological, social or organizational factors at work (Demerouti \& Bakker, 2011). The job requirementresource model provides there are two different action paths between job re- 
quirements and work resources, which are called health depletion process path and motivational process path respectively. From a more distant point of view, these two paths will affect organizational results, job requirements affect employees' in-role performance behavior through job burnout, and job resources predict employees' out-of-role performance behavior through job input. Specifically, the incentive path makes employees more goal-oriented and more focused on work tasks, which has a positive impact on job performance. On the contrary, health attrition or job burnout will make employees have no energy and resources to achieve their work goals. It has a negative impact on job performance. As for the relationship between job requirements and job resources, the job requirement-resource model holds that job resources can not only stimulate job input, but also reduce the impact of job requirements attrition and reduce job burnout (Breevaart et al., 2014). When the job requirements are high, the motivational role of work resources will be more significant, that is, when work resources are needed (high job requirements), they can play a more stimulating role, for example, in a difficult work environment, a positive organizational atmosphere will be more likely to promote work engagement. In addition, it is added that personal resources (such as optimism and self-efficacy) can play a role similar to work resources. Specifically, personal resources have a direct positive effect on work input and indirectly alleviate the negative impact of job requirements on personal attrition (Bakker \& Demerouti, 2017).

Based on this, we propose a research model as shown in Figure 1.

\subsection{Coaching Leadership and Employees' Innovation Behavior}

Employee innovation behavior is the process of generating new ideas and implementing them with useful ideas (Scott \& Bruce, 1994). As an out-of-role behavior with uncertainty and resource consumption, innovation behavior is the product of the interaction of individuals, leaders, work groups and other factors. Based on Job Demand-Resource Theory, work resources can positively predict employees' out-of-role performance behavior. As a prominent job resource, coaching leadership has a positive impact on employees' work performance and behavior (Bakker \& Demerouti, 2017), and has unique advantages in promoting innovative

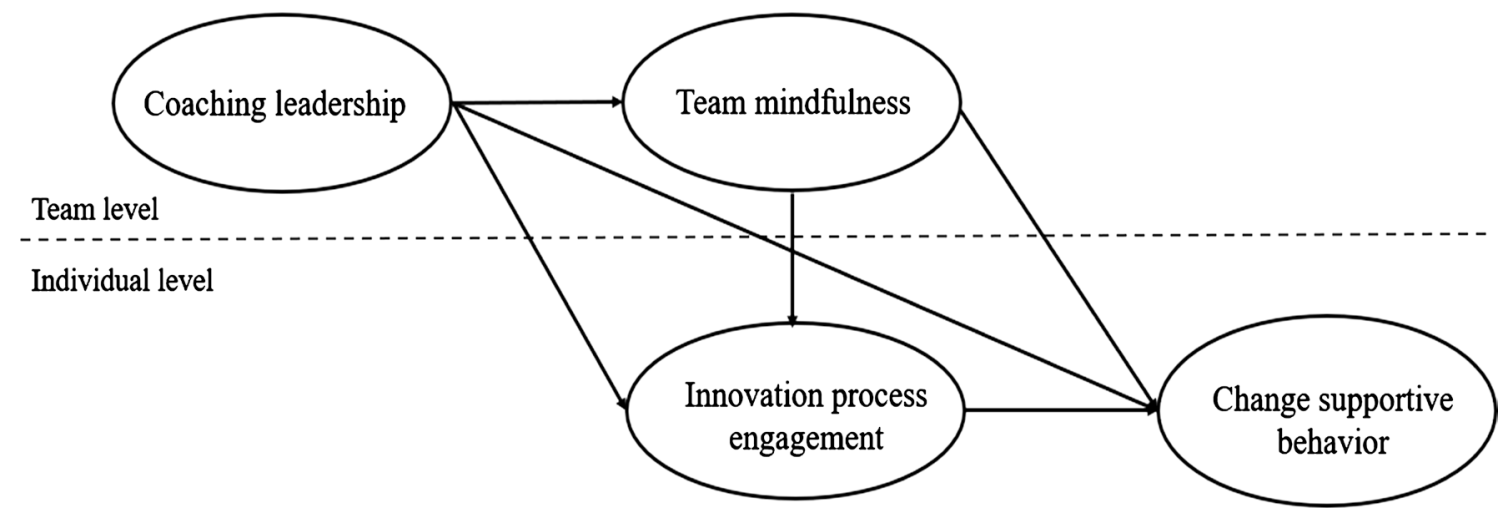

Figure 1. Research model. 
behavior. The key to innovation lies in the improvement and breakthrough of employees' mental model. Coaching leaders help employees discover their deepseated needs and set work goals by using effective coaching techniques such as authorization, inspiration, encouragement and guidance, and communicate and interact with employees openly, provide corresponding resources and support in the process of achieving their goals, attach importance to improving their mental model and stimulate their potential. This helps to stimulate the innovative potential of employees. In the implementation stage of innovative thinking, coaching leaders will help employees make corresponding action plans according to their goals, and help them master relevant skills and resources, so as to achieve innovative ideas and complete innovative behavior. Based on the above analysis, this study puts forward the following hypotheses:

Hypothesis 1: Coaching Leadership is positively related to employees' innovation behavior.

\subsection{Innovation Process Engagement as Mediator}

Innovation process engagement is the degree to which employees spontaneously focus their cognition, energy and behavior on innovation-related processes, such as problem identification, information search and coding, ideas and alternatives (Zhang \& Bartol, 2010; Amabile, 1983). The core hypothesis of the job requirement-resource model proposes that job resources, such as leadership support and empowerment, will affect employees' relevant state and behavior through motivational paths, and the most direct one will stimulate employees' work commitment, commitment and vitality, etc., and work resources are the direct predictors of employees' work engagement (Bakker \& Demerouti, 2017). As a very obvious and advantageous work resource, coaching leadership can promote employees' investment in problem identification, information retrieval and coding and generating preliminary ideas through questioning interaction and feedback, that is, employees may invest in a higher level of innovation process. When employees feel that they have received support and resources from leaders, they will be more motivated and spontaneously engage in investment related to innovation activities, with a higher level of investment in the innovation process (Yuan, Zhang, \& Tu, 2018). Based on the above analysis, this study puts forward the following hypotheses:

Hypothesis 2: Coaching leadership is positively related to employees' innovation process engagement.

Innovation process engagement is an important forerunner (Amabile, 1983) of innovation behavior results. When an employee has a high level of investment in the innovation process, it means that he will spend more time and effort to identify and solve problems than other less engaged colleagues, think about problems from multiple perspectives, are more likely to come up with new and useful ideas and ideas (Zhang \& Bartol, 2010), and will be more creative (Jiang \& Yang, 2015). Many studies have also proved that there is a positive relationship 
between employees' investment in innovation process and innovation behavior (Zhou \& Pan, 2015; Zhang \& Feng, 2016; Piyathasanan et al., 2018).

The theory of job requirement-resource model proposes that work resources will affect individual behavior and work results through motivational process paths. Work resources predict employees' positive work results through work engagement, especially out-of-role performance behavior. Specifically, incentive paths make employees more goal-oriented, can be more focused on work tasks, and have a positive impact on job performance (Bakker \& Demerouti, 2017). In the interaction with employees, coaching leaders will help and inspire employees to think about problems and set goals, and give feedback and resources to help employees achieve their goals, so that employees can be more focused on activities related to the innovation process. On the other hand, employees who invest more in the innovation process can put forward new ideas and new programs that can be implemented more creatively and reasonably, which will eventually be transformed into innovative behavior. Based on the above analysis, at the individual level, coaching leaders can have a positive impact on innovation behavior by promoting employees' engagement in the innovation process. Based on the above analysis, this study puts forward the following hypotheses:

Hypothesis 3: Innovation process engagement is positively related to innovation behavior.

Hypothesis 4: The positive relationship between coaching leadership and employees' innovation behavior is mediated by innovation process engagement.

\subsection{Team Mindfulness as Mediator}

Coaching leadership style will have an impact on the relevant variables at the team level. According to the resource preservation theory and the work requirement-resource model theory, individuals have the tendency to acquire and preserve their own resources, and the more resources they have, the easier it is to obtain resources. The connotation of mindfulness is "attention, awareness, and non-judgment of the stimuli of participation" (Brown et al., 2007). Team mindfulness is a common belief among team members that their interaction is awareness and attention to current events and experiences, and deal with team experiences in a non-critical manner (Yu \& Zellmer-Bruhn, 2018). As a supportive situation, coaching leadership provides more abundant work resources for the team, which makes the team more focused on what is happening at the moment, and the team has a higher level of mindfulness. At the same time, coaching leaders will form a non-judgmental attitude and belief in the team. Coaching leaders pay attention to the development and growth of employees and treat all employees equally. This style will develop an open, receptive and non-judgmental attitude within the team and promote the level of mindfulness in the team. Based on the above analysis, this study puts forward the following hypotheses:

Hypothesis 5: Coaching leadership is positively related to team mindfulness.

According to the point of view of the job requirement-resource model, work 
resources will have a positive impact on work results. Team mindfulness, as a common belief among team members, is a kind of work resource, which will have a positive impact on employee performance and positive behavior such as innovative behavior (Baas, Nevicka, \& Ten Velden, 2014; Vogus \& Welbourne, 2010). First of all, team mindfulness promotes the generation of new ideas. Teams with a high level of mindfulness will focus on the present, improve their observation and insight, and be able to analyze, think about problems, and come up with new ideas from different perspectives (Yu \& Zellmer-Bruhn, 2018). Secondly, a high level of mindfulness in the team is more conducive to the support and implementation of individual innovative ideas. The team will have a more open and non-judgmental attitude towards events, which is a kind of support and trust for employees to break through innovation, and the risk and uncertainty of innovation will be reduced.

According to the resource preservation theory and the work requirement-resource model theory, individuals have the tendency to acquire and preserve their own resources, and the more resources they have, the easier it is to obtain resources. As a positive work resource, coaching leaders will guide the team to maintain higher level of mindfulness, which as a kind of team resource, or a tool that can help to obtain resources (Zivnuska et al., 2016), maintains an open and objective attitude, which is a kind of support for innovation, contributes to the generation and realization of ideas, and promotes employees' innovative behavior. Based on the above analysis, we put forward the following hypotheses:

Hypothesis 6: Team mindfulness is positively related to employees' innovation behavior.

Hypothesis 7: The positive relationship between coaching leadership and employees' innovation behavior is mediated by team mindfulness.

\subsection{Team Mindfulness, Innovation Process Engagement and Employees' Innovation Behavior}

According to the theory of job requirement-resource model, job resources have a direct and positive impact on employees' input (Bakker \& Demerouti, 2017). As a working resource at the team level, team mindfulness will promote employees' input in the innovation process. Previous studies have pointed out that employees' investment in the innovation process is related to their cognitive skills in problem-solving or task-solving, interpersonal relationships with other colleagues at work, and communication atmosphere in the team (Zhou \& Pan, 2015). First of all, in teams with high mindfulness, team members maintain keen attention and awareness, focus more on work activities, and deal with problems in a more comprehensive manner (Leroy et al., 2013). These analytical skills and keen insight will promote employees' high participation and commitment to the innovation process. Secondly, in a team with a high level of mindfulness, team members follow the belief of non-judgment, and they will treat their colleagues' behavior more openly and objectively, and such interpersonal relationships will 
be more full of trust and cooperation. Interpersonal citizenship behavior is significantly higher than low-level teams, such a team is more conducive to employees' participation and innovation process activities.

Based on the above analysis, this study puts forward the following hypotheses to be verified:

Hypothesis 8: Team mindfulness is positively related to innovation process engagement.

According to the resource preservation theory and the work requirement-resource model theory, the more resources there are, the easier it is to obtain resources, and the work resources in the workplace will affect individual behavior and work results through the motivational process path, and work resources will promote employees to be more goal-oriented and more focused on work tasks, thus predicting employees' positive work results (Bakker \& Demerouti, 2017). In the above, we discussed that coaching leadership as a kind of work resource, under the leadership style of coaching leadership, which authorizes, guides and supports employee development, will also promote the formation of team resources, that is, team mindfulness. As a kind of work resource in the team, team mindfulness will give employees the necessary cognitive skills and good interpersonal atmosphere to invest in the innovation process. It has a positive impact on employees' investment in the innovation process, and ultimately affects employees' innovation behavior. Therefore, combined with the resource preservation theory and the job requirement-resource model theory, and combined with the above discussion on the relationship between coaching leadership, team mindfulness, employee innovation process input and innovation behavior, this study puts forward the hypothesis:

Hypothesis 9: Team mindfulness and employee innovation process engagement play a chain intermediary role in the relationship between coaching leadership and employee innovation behavior.

\section{Method}

The object of this questionnaire survey is mainly from the working team of enterprises in South China, using a three-stage, multi-source paired sample survey, the survey object is the team leader in the enterprise and more than 3 subordinates. In this study, 90 data samples about coaching leadership styles were obtained. Three months later, the second time to collect data, through the team leader to contact the team subordinates, collect the self-evaluation data of the team subordinates and their work team, and obtain 268 valid data. Another three-month interval, the third time to collect data, get 88 leaders filled out 262 points of employee change support behavior questionnaire, eliminate the invalid questionnaire, and finally get 88 team leaders and 259 subordinates matching data.

\subsection{Measure}

Coaching leadership behavior. The Coaching leadership behavior scale adopts the one-dimensional scale developed by Anderson (2013). The scale is a sin- 
gle-dimensional scale composed of 12 items, of which the fourth and sixth items are scored in reverse, such as "I will help the personal development of subordinates". Instead of directly giving solutions "and" I will actively create training/learning opportunities to improve the work skills of subordinates. The Cronbach $\alpha$ is $.76 . \chi^{2} / \mathrm{df}=1.78, \mathrm{CFI}=.86, \mathrm{TLI}=.85$, SRMR $=.08, \mathrm{RMSEA}=.08$.

Team mindfulness. The team mindfulness scale uses the two-dimensional scale developed by Yu and Zellmer-Bruhn (2018) for team mindfulness, which is divided into two dimensions: "focus on the present" and "the process of not judging the experience". Each dimension is measured by 5 item items, and a total of 10 items make up the team mindfulness scale, such as "it is easy for our team to focus on what is happening right now". The Cronbach $\alpha$ is $.78 . \chi^{2} / \mathrm{df}=$ $2.02, \mathrm{CFI}=.84, \mathrm{TLI}=.81, \mathrm{SRMR}=.08$, RMSEA $=.08$.

Innovation process engagement. The innovation process engagement scale adopts the three-dimensional scale developed by Zhang and Bartol (2010), which is divided into three dimensions: "problem identification", "information retrieval and coding" and "creativity generation". The first two dimensions are measured by three-item items, and the third dimension is measured by fiveitem items. A total of 11 items constitute the innovation process input scale, such as "I will spend a lot of time thinking about the essence of the problem". The Cronbach $\alpha$ is .83. $\chi^{2} / \mathrm{df}=1.72, \mathrm{CFI}=.89, \mathrm{TLI}=.85, \mathrm{SRMR}=.07$, RMSEA $=.08$.

Innovation behavior. The innovative behavior scale adopts the one- dimensional scale developed by Scott and Bruce (1994). It uses six items to measure employees' innovative behavior, such as "the employee will actively explore new ideas in technology, process, tools and products". The Cronbach $\alpha$ is $.92 . \chi^{2} / \mathrm{df}$ $=.90, \mathrm{CFI}=1.00, \mathrm{TLI}=1.01, \mathrm{SRMR}=.02, \mathrm{RMSEA}=.00$.

\subsection{Result}

Descriptive statistics of variables are reported in Table 1. We conducted multilevel confirmatory factor analysis to examine whether promotive and prohibitive team voice represented distinct constructs (simultaneously at within and between team levels). The six-factor model fit the data well $\left(\chi^{2} / \mathrm{df}=1.72, \mathrm{CFI}=.89, \mathrm{TLI}=.88\right.$, SRMR $=.06$, RMSEA $=.05$ ).

Based on the construction of the research theoretical model, this study takes coaching leadership as independent variable (team level), team mindfulness (team level) and employee innovation process input as mediating variables, and innovation behavior as dependent variable to construct a multi-level and cross- level structural equation model (MSEM), at the individual level and team level. The gender, age, working years, education level and working time with subordinates are taken as control variables to test the double intermediary relationship between team mindfulness and employee innovation process between coaching leadership and innovative behavior. The analysis results of each path of the cross-hierarchical structural equation model are shown in Figure 2. 
First of all, coaching leadership has a significant positive direct impact on employees' innovation behavior $(\mathrm{c}=.40, p<.01)$, hypothesis 1 is further verified. Secondly, coaching leaders also have a significant positive impact on employees' innovation process engagement $\left(a_{1}=.24, p<.001\right)$, which further verifies hypothesis 2; employees' innovation process engagement has a significant positive impact on innovation behavior $\left(\mathrm{b}_{1}=.48, p<.05\right)$, thus hypothesis 3 is further verified. Coaching leadership has a significant positive effect on team mindfulness $\left(\mathrm{a}_{2}=.28, p<.01\right)$, which further validates hypothesis 5 ; team mindfulness has a significant positive impact on employees' innovation behavior $\left(\mathrm{b}_{2}=.43, p\right.$ $<.001$ ), and hypothesis 6 is further verified; finally, the impact of team mindfulness on employees' investment in innovation process is also significantly positive $(\mathrm{d}=.51, p<.001)$, and hypothesis 8 is further verified.

The intermediary effect of coaching leadership on innovation behavior through employee innovation process input is also significant $\left(\mathrm{a}_{1} \mathrm{~b}_{1}=.12, p\right.$ $<.05)$, and the direct effect $c$ of coaching leadership on innovation behavior is

Table 1. Descriptive statistics and correlations for study variables.

\begin{tabular}{|c|c|c|c|c|c|c|c|c|c|}
\hline Variables & 1 & 2 & 3 & 4 & 5 & 6 & 7 & 8 & 9 \\
\hline $1 \mathrm{CL}$ & (.79) & & & & & & & & \\
\hline $2 \mathrm{TM}$ & $.22^{* *}$ & $(.85)$ & & & & & & & \\
\hline $3 \mathrm{IPE}$ & $.26^{* *}$ & $.62^{* *}$ & $(.92)$ & & & & & & \\
\hline $4 \mathrm{IB}$ & $.35^{* *}$ & $.36^{* *}$ & $.40^{* *}$ & $(.91)$ & & & & & \\
\hline 5 F-Gender & .07 & .07 & -.02 & -.02 & & & & & \\
\hline 6 F-Age & -.02 & .02 & .04 & .08 & -.11 & & & & \\
\hline 7 F-Education & .05 & .10 & .09 & .03 & -.11 & .05 & & & \\
\hline 8 F-Time & -.02 & -.03 & -.05 & -.10 & -.11 & $.76^{* *}$ & -.02 & & \\
\hline $9 \mathrm{~W}$-Time & $-.17^{* *}$ & $-.014^{*}$ & $-.20^{*}$ & -.08 & .03 & $.30^{* *}$ & .06 & $.23^{* *}$ & \\
\hline$M$ & 4.10 & 4.03 & 4.10 & 3.75 & 1.50 & 2.14 & 2.83 & 2.88 & 1.85 \\
\hline$S D$ & .38 & .49 & .51 & .76 & .50 & 5.52 & .69 & 1.41 & .72 \\
\hline
\end{tabular}

${ }^{* *} p<.01 ;{ }^{*} p<.05$.

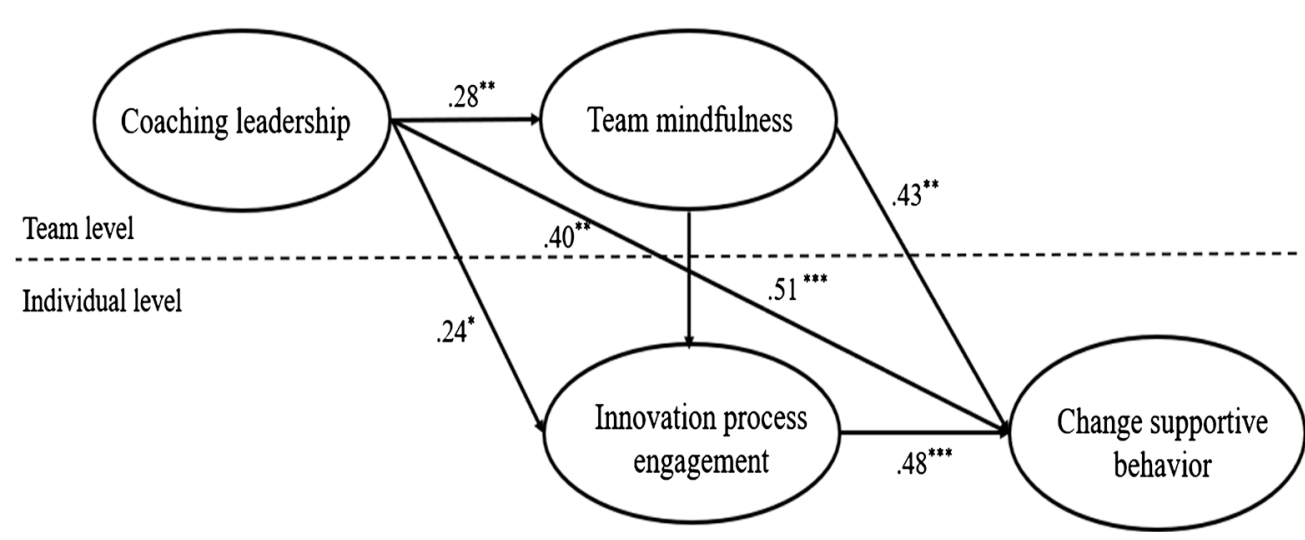

Figure 2. Analysis diagram of multi-level structural equation model. 
also significant, so the intermediary effect of employee innovation process input is also established. Hypothesis 4 is supported by partially mediating the impact of coaching leadership on employees' innovation behavior. Secondly, the mediating effect of coaching leadership on innovative behavior through team mindfulness is significant $\left(\mathrm{a}_{2} \mathrm{~b}_{2}=.12, p<.05\right)$, so the mediating effect of team mindfulness is established, so the influence of coaching leadership on employees' innovative behavior is partly mediated by team mindfulness. Hypothesis 7 is supported. Thirdly, team mindfulness has a direct and significant positive impact on innovation behavior, and the chain intermediary effect of coaching leaders on innovation behavior through team mindfulness and employee innovation process input is also significant $\left(\mathrm{a}_{2} \mathrm{db}=.07, p<.001\right)$. Hypothesis 9 is supported. Finally, coaching leaders work together on innovation behavior through team mindfulness and employee innovation process input, and team mindfulness will further promote employees' innovation process input to stimulate employees' innovation behavior. The total effect of this model is also very significant (tot $=.70, p<.001$ ), and the whole model has been verified. The analysis results of MSEM are shown in Table 2.

\section{Discussion}

\subsection{Theoretical Implications}

Firstly, it enriches the research on the internal mechanism of coach-type leadership and promotes the improvement and development of the theory of coach-type leadership. The existing research on leadership behavior is still on the rise, more stay in the main effect of coaching leadership, there is little research on its specific internal mechanism, and has not yet formed a widely recognized theoretical model. This study discusses the positive effect of coaching leadership on innovative behavior, improves and verifies the possible intermediary mechanism, which is helpful to promote the improvement of coaching

Table 2. Results of MSEM.

\begin{tabular}{ccc}
\hline Path & Coefficient & $S D$ \\
\hline CL-IPE & $.24^{*}$ & .10 \\
IPE-IB & $.48^{* *}$ & .14 \\
CL-TM & $.28^{* *}$ & .10 \\
TM-IB & $.43^{* *}$ & .14 \\
CL-IB & $.40^{* *}$ & .13 \\
TM-IB & $.51^{* *}$ & .10 \\
Mediating 1 (IPE) & $.12^{*}$ & .05 \\
Mediating 2 (TM) & $.12^{*}$ & .05 \\
Mediating 3 & $.07^{* *}$ & .03 \\
Total & $.70^{* *}$ & .15 \\
\hline
\end{tabular}

${ }^{* * *} p<.001 ;{ }^{* *} p<.01 ;{ }^{*} p<.05$. 
leadership research and theoretical development.

Secondly, it fills the gap in the intermediary mechanism of comprehensively discussing coaching leadership and innovative behavior from the two levels of team and individual. At present, in the research on leadership and employee innovation, most of them stay at a single level, while there are few cross-layer studies considering different levels. However, employees' innovative behavior is driven by a variety of factors, and single-layer variables can't play a decisive role. Therefore, this study starts from the team and individual levels at the same time, discusses how coaching leaders influence and ultimately affect employees' innovative behavior at the team level and individual level, and broadens the research methods of the intermediary mechanism of coaching leadership. It fills the deficiency of the single level of leadership and employee innovation research.

Thirdly, the function mechanism of coaching leadership is studied from the new perspective of job requirement-resource theory model. At the same time, the job requirement-resource theory model is introduced into the research of leadership topic, which expands the application of job requirement-resource theory model in the field of leadership (Bakker \& Demerouti, 2017). As a kind of work situation, leaders also affect the different intensity of work resources and work requirements in employees' work environment, which indirectly affects employees' feelings and work performance (Breevaart et al., 2014).

\subsection{Practical Implications}

First of all, enterprises can pay more attention to managers' coaching consciousness in the recruitment process, and select leaders who are willing to inspire, give feedback and promote the growth of subordinates to complete the work. In addition, enterprises can regularly carry out relevant training courses to train and improve the level of coaching leadership of leaders, such as learning how to better motivate, inspire and guide subordinates, stimulate their potential, and improve their ability and work performance; leaders should give subordinates more room for trial and error and growth, and give feedback and guidance to their work and new ideas.

Secondly, leaders in the team should put more emphasis on the focus and attention of things, and deal with all kinds of things in the team with a more open and objective attitude, and lead themselves as an example to promote the formation of mindfulness beliefs in the team. In addition, team members can also carry out relevant mindfulness training to improve their own mindfulness level and influence each other to improve the team mindfulness level.

Finally, enterprises should provide conditions for employees to carry out activities related to the innovation process, such as giving employees available information and channels when they want to obtain more professional knowledge, or when they want to search and code the relevant information of the identified problems, there are no restrictions on employees' relevant learning and exploration. Leaders can give direction guidance and feedback to help employees carry 
out related activities more clearly and effectively, and also make employees more confident and motivated to carry out activities related to the innovation process.

\section{Limitations}

Several limitations of our study that point to future research directions should be noted. First of all, most of the measurement tools of this study come from scales developed in the field of western management. Although the effectiveness of these scales has been verified in China, they may still be affected by cultural factors. It is necessary for future research to consider selecting or developing localization scales suitable for Chinese oriental situations in order to promote the effectiveness of the research. Secondly, the samples of the questionnaire survey in this study are mainly from enterprises in South China, the sample collection is not comprehensive enough, and the applicability of the research results in other parts of China still needs to be tested. Finally, although the multi-source methods of tracking and pairing samples are used to collect data in this questionnaire study, and the variation of homologous methods is controlled to some extent, subjective errors are inevitable in using the questionnaire to collect data.

\section{Conflicts of Interest}

The author declares no conflicts of interest regarding the publication of this paper.

\section{References}

Amabile, T. M. (1983). The Social Psychology of Creativity: A Componential Conceptualization. Journal of Personality and Social Psychology, 45, 357-376. https://doi.org/10.1037/0022-3514.45.2.357

Anderson, V. (2013). A Trojan Horse? The Implications of Managerial Coaching for Leadership Theory. Human Resource Development International, 16, 251-266. https://doi.org/10.1080/13678868.2013.771868

Baas, M., Nevicka, B., \& Ten Velden, F. S. (2014). Specific Mindfulness Skills Differentially Predict Creative Performance. Personality \& Social Psychology Bulletin, 40, 1092-1106. https://doi.org/10.1177/0146167214535813

Bakker, A. B., \& Demerouti, E. (2017). Job Demands-Resources Theory: Taking Stock and Looking Forward. Journal of Occupational Health Psychology, 22, 273-285. https://doi.org/10.1037/ocp0000056

Breevaart, K., Bakker, A. B., Demerouti, E., Sleebos, D. M., \& Maduro, V. (2014). Uncovering the Underlying Relationship between Transformational Leaders and Followers' Task Performance. Journal of Personnel Psychology, 13, 194-203. https://doi.org/10.1027/1866-5888/a000118

Brown, K. W., Ryan, R. M., \& Creswell, J. D. (2007). Mindfulness: Theoretical Foundations and Evidence for Its Salutary Effects. Psychological Inquiry, 18, 211-237. https://doi.org/10.1080/10478400701598298

Demerouti, E., \& Bakker, A. B. (2011). The Job Demands-Resources Model: Challenges for Future Research. SA Journal of Industrial Psychology, 37, a974.

https://doi.org/10.4102/sajip.v37i2.974 
Demerouti, E., Nachreiner, F., Bakker, A. B., \& Schaufeli, W. B. (2001). The Job Demands-Resources Model of Burnout. Journal of Applied Psychology, 86, 499-512. https://doi.org/10.1037/0021-9010.86.3.499

Jiang, J., \& Yang, B. (2015). Roles of Creative Process Engagement and Leader-Member Exchange in Critical Thinking and Employee Creativity. Social Behavior \& Personality: An International Journal, 43, 1217-1231. https://doi.org/10.2224/sbp.2015.43.7.1217

Jung, D. I., Chow, C., \& Wu, A. (2003). The Role of Transformational Leadership in Enhancing Organizational Innovation: Hypotheses and Some Preliminary Findings. Leadership Quarterly, 14, 525-544. https://doi.org/10.1016/S1048-9843(03)00050-X

Leroy, H., Anseel, F., Dimitrova, N. G., \& Sels, L. (2013). Mindfulness, Authentic Functioning, and Work Engagement: A Growth Modeling Approach. Journal of Vocational Behavior, 82, 238-247. https://doi.org/10.1016/j.jvb.2013.01.012

Özduran, A., \& Tanova, C. (2017). Coaching and Employee Organizational Citizenship Behaviors: The Role of Procedural Justice Climate. International Journal of Hospitality Management, 60, 58-66. https://doi.org/10.1016/j.ijhm.2016.10.004

Piyathasanan, B., Mathies, C., Patterson, P., \& Ruyter, K. D. (2018). The Value of Crowd-Sourcing: Antecedents and Value Creation of Creative Process Engagement. Journal of Service Marketing, 32, 19-33. https://doi.org/10.1108/JSM-02-2017-0044

Sacramento, C. A., Fay, D., \& West, M. A. (2013). Workplace Duties or Opportunities? Challenge Stressors, Regulatory Focus, and Creativity. Organizational Behavior \& Human Decision Processes, 121, 141-157. https://doi.org/10.1016/j.obhdp.2013.01.008

Scott, S. G., \& Bruce, R. A. (1994). Determinants of Innovative Behavior: A Path Model of Individual Innovation in the Workplace. Academy of Management Journal, 37, 580-607. https://doi.org/10.2307/256701

Smither, J. W., London, M., Flautt, R., Vargas, Y., \& Kucine, I. (2003). Can Working with an Executive Coach Improve Multisource Feedback Ratings over Time? A Quasi Experimental Field Study. Personnel Psychology, 56, 23-44. https://doi.org/10.1111/j.1744-6570.2003.tb00142.x

Vogus, T. J., \& Welbourne, T. M. (2010). Structuring for High Reliability: HR Practices and Mindful Processes in Reliability-Seeking Organizations. Journal of Organizational Behavior, 24, 877-903. https://doi.org/10.1002/job.221

Yu, L., \& Zellmer-Bruhn, M. (2018). Introducing Team Mindfulness and Considering Its Safeguard Role against Conflict Transformation and Social Undermining. Academy of Management Journal, 61, 324-347. https://doi.org/10.5465/amj.2016.0094

Yuan, L., Zhang, L. L., \& Tu, Y. H. (2018). When a Leader Is Seen as Too Humble: A Curvilinear Mediation Model Linking Leader Humility to EMPLOYEE CREATIVE Process Engagement. Leadership \& Organization Development Journal, 39, 468-481. https://doi.org/10.1108/LODJ-03-2017-0056

Zhang, W. W., \& Feng, T. T. (2016). The Effect of Psychological Capital on Employee Creativity: The Role of Creative Process Engagement and the Learning Goal Orientation. 2016 3rd International Conference on Management Innovation and Business Innovation (ICMIBI 2016), 58, 803-808.

Zhang, X., \& Bartol, K. M. (2010). The Influence of Creative Process Engagement on Employee Creative Performance and Overall Job Performance: A Curvilinear Assessment. Journal of Applied Psychology, 95, 862-873. https://doi.org/10.1037/a0020173

Zhou, Q., \& Pan, W. (2015). A Cross-Level Examination of the Process Linking Transformational Leadership and Creativity: The Role of Psychological Safety Climate. $\mathrm{Hu}$ man Performance, 28, 405-424. https://doi.org/10.1080/08959285.2015.1021050 
Zivnuska, S., Kacmar, K. M., Ferguson, M., \& Carlson, D. S. (2016). Mindfulness at Work: Resource Accumulation, Well-Being, and Attitudes. Career Development International, 21, 106-124. https://doi.org/10.1108/CDI-06-2015-0086 